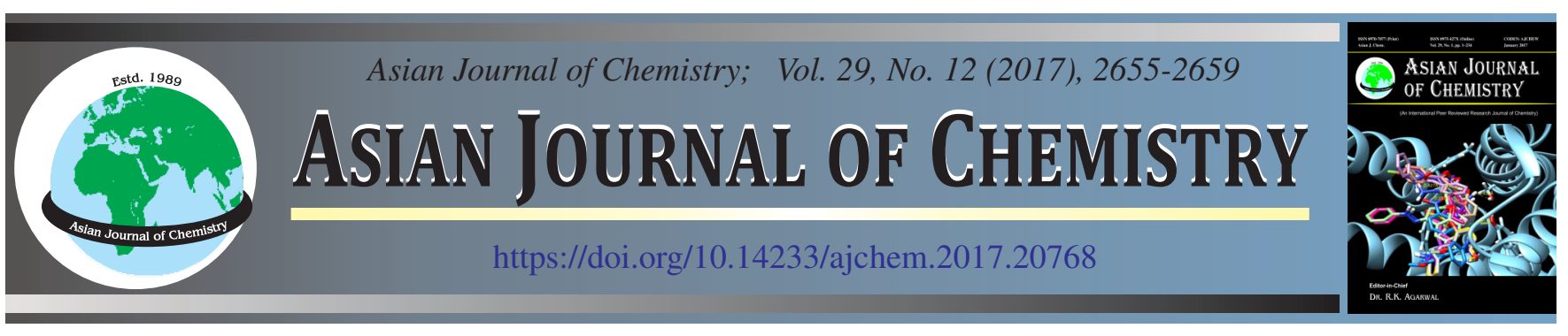

\title{
Oxidative Stability of Extra Virgin Olive Oil with Natural Plant Extracts during Microwave Heating
}

\author{
Amira Yahyaoui ${ }^{1}$, Ghayth Rigane ${ }^{1,2}$ and Ridha Ben SAlem ${ }^{1, *}$
}

${ }^{1}$ Organic Chemistry Laboratory LR17ES08, Department of Chemistry, Faculty of Sciences, University of Sfax, B.P. 1171, 3038 Sfax, Tunisia ${ }^{2}$ Department of Physics and Chemistry, Facultyof Sciences and Technology, University of Kairouan, B.P. 380, 9100 Sidi Bouzid, Tunisia

*Corresponding author: E-mail: ridhabensalem@yahoo.fr

Received: 8 May 2017;

Accepted: 9 August 2017;

Published online: 30 October 2017;

AJC-18610

\begin{abstract}
The aim of this work was to provide a careful study on the assessment of olive oil thermal processing after enrichment with aqueous extract of aromatic plants and olive leaves, in order to ascertain the optimal settings for maximization of olive oil quality, while delaying the onset of oxidation products with detrimental health impacts. The present work intend to study the potential increased olive oil oxidative stability, under microwave heating at different exposure time, induced by natural plant extracts. All studied oil samples exhibited a high stability when microwave treatment did not exceed $5 \mathrm{~min}$. The use of natural antioxidants could be an effective way to protect extra virgin olive oil from oxidation when treated by microwaves.
\end{abstract}

Keywords: Microwave, Extra virgin olive oil, Aromatic plants, Phenolic content.

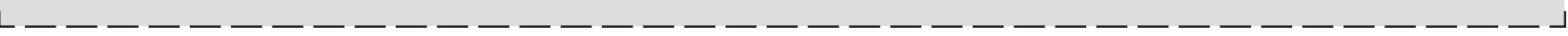

\section{INTRODUCTION}

Microwave heating is a common and fast procedure for food preparation and manufacturing. Its effects on macro- and micro-components, as well as on flavour formation and colour changes in several foods, have been extensively evaluated [1]. More recently, Yahyaoui et al. [2] and Malheiro et al. [3] mentioned that microwave heating caused severe quality, nutritional and compositional losses, mainly after 3 min of heating, with an increase in peroxide value and UV spectrophtometric constants. Additionly, many vegetable oils subjected to microwave heating with different exposure times and powers exhibited some chemical effects: free fatty acids moderately increased in microwaved vegetable oils as a consequence of fat hydrolysis and tocopherols decreased [4].

According to Peñalvo et al. [5], aromatic herbs have been used since ancient times in applications. Among their therapeutic properties, they are well known by their antioxidant activity against some human diseases. For these reasons, Moldao-Martins et al. [6] and Asensio et al. [7] proposed that essential oils could be added to the oils via a simple procedure. Rosenblant et al. [8] enriched extra virgin olive oil by dissolving green tea into the oil while Koprivnjak et al. [9] enriched virgin olive oil directly with phospholipids without any mechanical processes. Additionally, Rubió et al. [10] studied the effect of adding phenolic extracts from olive paste and thyme to virgin olive oil. While, Ayadi et al. [11] obtained various flavoured olive oils by adding aromatic plants to virgin olive oil and gentle stirring for $2 \mathrm{~h}$. Current Tunisian research team stored the mixture into closed vessel for two weeks prior to analysis of its physico-chemical properties and stability. However, there is no sufficient information in the literature about microwave heating effect on extra virgin olive oil enriched with aromatic plant extract or olive leaves one.

It is well known that Mentha spicata L., Rosemary officinalis L., Thymus vulgaris L., Ocimum basilicum L., Pelargonium graveolens L'Hér. are some of the aromatic plants which provide essential oil, vitamins, minerals and phytochemicals (bioactive substances present in small quantities that act, for instance, as antioxidants, bactericides or antivirals). Within phytochemicals, phenolic compounds are one of the major groups contribute for aromatic plants properties, including the prevention of cardiovascular disease and cancer. Although aromatic plants are consumed in low amounts, the biological impact of their intake cannot be ignored [12].

In view of the above, the present study aimed to investigate the possibilities and likely effects of the application of added phenolic compounds extracted from some medicinal plants such as Mentha spicata L., Rosemary officinalis L., Thymus vulgaris L., Ocimum basilicum L., Pelargonium graveolens $L$ 'Hér., commonly cultivated in Sfax located in the South of Tunisia as well as the Chemlali olive leaves extract to extra virgin olive oil under microwave heating, during different exposure periods $(0,1,3,5,10$ and $15 \mathrm{~min})$. Several quality 
parameters were studied: free acidity, peroxide value, spectrophotometric constants and composition of chlorophyll, carotenoids and total phenolic contents.

\section{EXPERIMENTAL}

All the solvents (HPLC grade) were purchased from Merck KGaA (Darmastadt, Germany) and from Riedel-de Haën (Steinhein, Germany). Potassium iodide (>99.0\%) was purchased from Chem-Lab (Zedelgem, Belgium). Sodium hydroxide (> $99 \%$ ) was supplied by Scharlau (Chemie, S.A, Spain). Acetic acid $(100 \%)$ and chloroform (> 99.1\%) were from Prolabo (AnalaR NORMAPUR, France). Folin-Ciocalteu reagent was obtained from Fluka (Buchs, Switzerland).

Olive fruit samples and maturity index: Olive drupes of Chemlali variety (Olea europaea L.), obtained from the city of Sfax, picked by hand during the 2015/2016 campaign. In order to eliminate the influence of maturation state on olive oil quality, the studied olive fruit were harvested at full maturation. The samples were collected from all sides of the tree, for a total amount $20 \mathrm{kgs}$ (number of analyzed samples, $\mathrm{n}=3$ ). After the olives transferred to laboratory, a batch was used for oil extraction, another batch was stored at $-80^{\circ} \mathrm{C}$ for the analysis. The maturity index was determined according to the method developed by the Agronomic Station of Jaén as function of fruit colour in both skin and pulp. The maturity index was determined on 100 randomly selected olives from each sample [13].

Procedure for extraction of phenolic compounds from some medicinal plants: Experiments were carried out on some medicinal plants viz., Mentha spicata L., Rosemary officinalis L., Thymus vulgaris L., Ocimum basilicum L., Pelargonium graveolens L'Hér., commonly cultivated in Sfax (South of Tunisia) as well as Chemlali olive leaves. Ethanol was added to olive leaves $(100 \mathrm{~g})$ and this was left to stand overnight under agitation in the dark. Subsequently, the solution was filtered through 0.45 $\mu \mathrm{m}$ Whatman filter paper. The extract was concentrated in vacuum drying at $35^{\circ} \mathrm{C}$ and the residue obtained was redissolved in $5 \mathrm{~mL}$ of ethanol and stored in glass vials at $0{ }^{\circ} \mathrm{C}$ in darkness until its use.

Description of samples: Seven samples of extra virgin olive oil were prepared as follows: The first was considered as control (non-enriched extra virgin olive oil) while the other samples were enriched with $400 \mathrm{mg} \mathrm{kg}^{-1}$ of phenolic rich extract. Weighed quantities of extracts (dissolved in $1 \mathrm{~mL}$ of ethanol) to obtain the desired final concentration (400 $\mathrm{mg} \mathrm{kg}^{-1}$ ). Then, these were added to extra virgin olive oil and stirred for $2 \mathrm{~h}$ in the darkness at room temperature. The samples were stored in the dark, in full filled dark until its use (not more than $24 \mathrm{~h}$ before heating treatment using microwaves apparatus). All samples were analyzed three times.

Heating procedure: To simulate conventional times used in home cooking, different times for microwave heating were selected: 1, 3, 5, 10 and 15 min. For each olive oil and heating time, three sub-samples of $50 \mathrm{~mL}$ were individually placed in a Petri dish (20 mm high and $110 \mathrm{~mm}$ of diameter) and subjected to heating in a microwave oven (Kenwood) at maximum power (1000 Watt). Unheated olive oil was used as control (corresponding to $0 \mathrm{~min}$ ). Afterwards, the samples were kept in Falcon tubes and refrigerated at $4{ }^{\circ} \mathrm{C}$ until analysis [2].

\section{Analytical methods}

Quality indices determinations: The titratable acidity (free fatty acids), UV spectrophotometric constants ( $\mathrm{K}_{232}$ and $\mathrm{K}_{270}$ ) and peroxides were determined according to the method proposed by ISO660 (1996). While peroxides were determined according to the method proposed by ISO3960 (2001). Next, carotenoids and chlorophylls ( $\mathrm{mg} / \mathrm{kg}$ of oil) were determined at 470 and $670 \mathrm{~nm}$, respectively, in cyclohexane using the specific extinction values according to the method of MínguezMosquera, et al. [14].

Extraction of phenolic fraction from olive oil: The phenolic compounds of virgin olive oil were extracted by adapting the procedure developed by Ocakoglu et al. [15] with some modifications. Briefly, the oil sample ( $4 \mathrm{~g}$ ) was added to $2 \mathrm{~mL}$ of $n$-hexane and $4 \mathrm{~mL}$ of a methanol/water $(60: 40, \mathrm{v} / \mathrm{v})$ solution in a $20 \mathrm{~mL}$ centrifuge tube. The obtained extract was separated by centrifugation for $3 \mathrm{~min}(6000 \mathrm{rpm})$. The hydroalcoholic phase was collected and the hexanic phase was re-extracted twice with $4 \mathrm{~mL}$ of methanol/water $(60: 40, \mathrm{v} / \mathrm{v})$ solution each time. Finally, the hydroalcoholic fractions were combined, washed with $4 \mathrm{~mL}$ of $n$-hexane to remove the residual oil, then concentrated and dried by evaporative centrifuge in vacuum at $35^{\circ} \mathrm{C}$.

Determination of total phenolics: Briefly, $50 \mu \mathrm{L}$ of phenolic extract was mixed with the Folin-Ciocalteau reagent $(250 \mu \mathrm{L})$ and with an aqueous solution of $\mathrm{Na}_{2} \mathrm{CO}_{3}(500 \mu \mathrm{L}, 20$ $\%)$. The mixture was vortexed and diluted with water to final volume of $5 \mathrm{~mL}$. The total phenolic content was determined colourimetrically at $765 \mathrm{~nm}$. The standard curve was prepared using diluted solutions of gallic acid in a methanol: water solution $(70: 30, \mathrm{v} / \mathrm{v})$. The total phenolic content was expressed as milligrams of gallic acid (GA) equivalents per kilogram of oil. For gallic acid, the curve absorbance versus concentration was described by the equation $y=0.095 x\left(r^{2}=0.973\right)[2]$.

Statistical analysis: The findings of this study were given as means of triplicate data with their standard deviations. Analysis of data was carried out using one-way ANOVA. Duncan's multiple test also used to separate significant differences between means at the $p<0.05$ significance level by using "Windows SPSS 15 Software".

\section{RESULTS AND DISCUSSION}

Quality parameters: In order to assess the effect of microwave heating in the quality of extra virgin olive oil, samples enriched by aromatic plant as well as olive leaves aqueous extracts, free acidity (FA), peroxide value (PV), coefficients of extinction at 232 and $270 \mathrm{~nm}\left(\mathrm{~K}_{232}\right.$ and $\left.\mathrm{K}_{270}\right)$ were evaluated (Figs. 1-3).

Regarding the free acidity, a narrow variation was observed in all treated samples for the three first minutes, ranging between 0.1 and $0.4 \%$. In a general way the free acidity values observed in the samples with aromatic plants and olive leaves extracts exhibited a significant increase after $10 \mathrm{~min}$ of microwaves treatments. It is worth noting that free acidity values results from the occurrence of hydrolysis in fatty acids. In those reactions hydrolytic enzymes are involved. Normally, these enzymes are presents in the olive fruit or surrounding microorganisms. In the present work, it is concluded that 


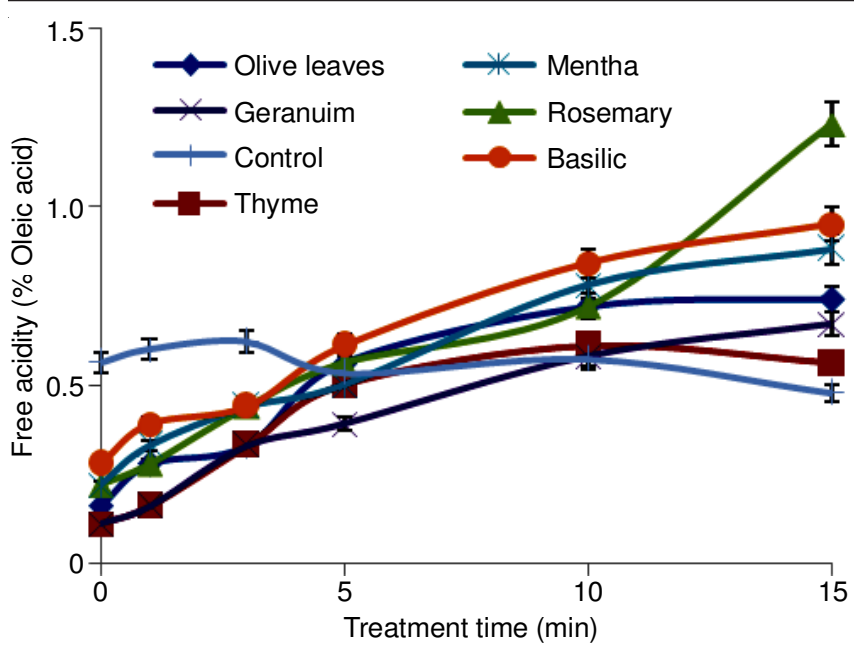

Fig. 1. Change in free acidity of enriched olive oils during microwaves treatment. The SD values were more than $5 \%$. Limits established for the extra-virgin olive oil by EEC (2003) [Ref. 16]: free acidity $\leq 0.8 \%$ of oleic acid

after 10 min of treatment, the probability of enzymes occurrence existent.

The analysis of peroxides performed in the present study indicated that, the oils enriched with olive leaves extract exhibited the lowest peroxide value value even if sample was treated by microwaves for $15 \mathrm{~min}$ (Fig. 2). On the other hand, it can be observed in Fig. 2, peroxide values of olive oil with aromatic plant extracts (not for oil with Rosemary officinalis L. and Ocimum basilicum L.) were below the limit of 20 meq $\mathrm{O}_{2} \mathrm{~kg}^{-1}$ set by the EEC regulations [16] for 5 min of treatments then it increased to attain $47 \mathrm{meq} \mathrm{O}_{2} \mathrm{~kg}^{-1}$ after $15 \mathrm{~min}$ of treatment. Our results were in accordance with those reported by Malheiro et al. [17]. This research team mentioned that the addition of white tea and olive leaves aqueous extracts to soybean oil were evaluated as possible oxidative stabilizers.

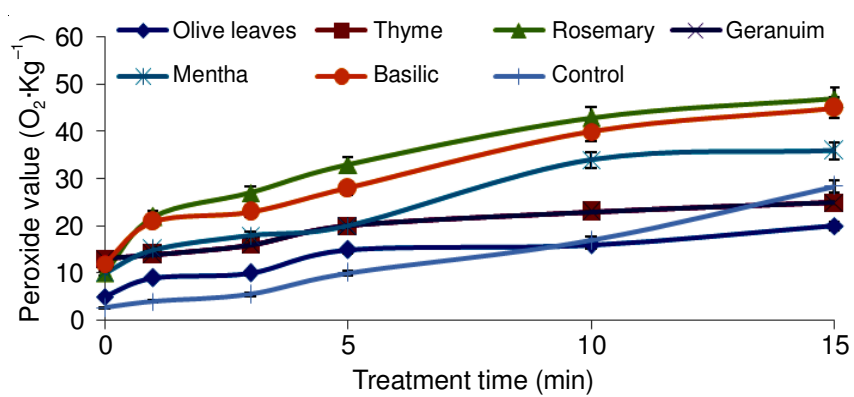

Fig. 2. Change in peroxide value of enriched olive oils during microwaves treatment. The SD values were more than $5 \%$. Limits established for the extra-virgin olive oil by EEC (2003) [Ref. 16]: peroxide value $\leq$ 20 meq $\mathrm{O}_{2} \mathrm{~kg}^{-1}$

$\mathrm{K}_{232}$ and $\mathrm{K}_{270}$ represent supplementary oil quality parameters. They are related to the primary and secondary oxidation products, respectively. The oils obtained with aromatic plants as well as olive leaf extracts showed different trends in $\mathrm{K}_{232}$. In the control sample, $\mathrm{K}_{232}$ increased from 0.6 to 4 (data not shown). In fact, olive oil with olive leaves, thyme and basilic extracts increased significantly over the first 5 min of treatment (Fig. 3). However, this interesting coefficient increase to exceed the limit of 0.22 set by the EEC regulations [16] after just 1 min of treatment for oils enriched with Mentha spicata L., Rosemary officinalis L. and Pelargonium graveolens L' Hér. aqueous extracts. From Fig. 3, it is worthnoting that the trend of $\mathrm{K}_{270}$ increase significantly for all the treated olive oils and do not exceed the limit 2.5 as indicated by EEC regulations [16].
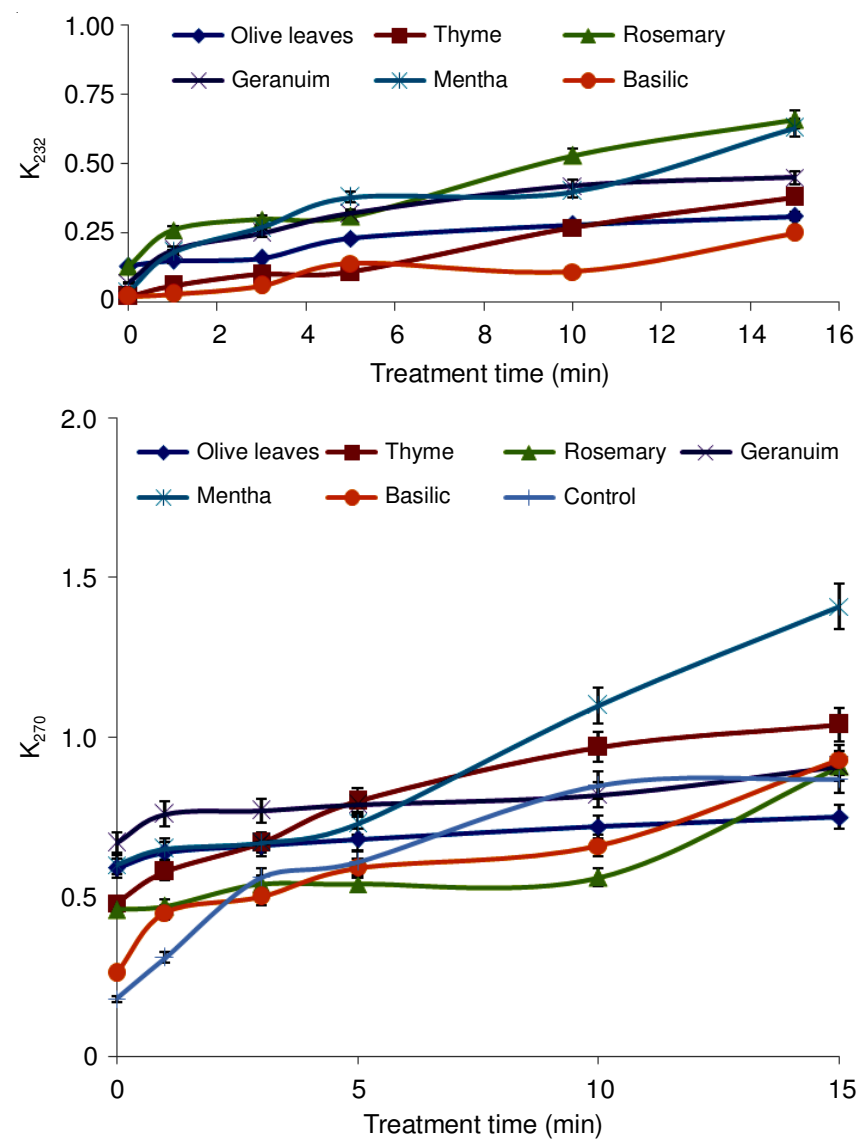

Fig. 3. Changes in the content of conjugated fatty acids measured by the specific extinction coefficient at $232 \mathrm{~nm}\left(\mathrm{~K}_{232}\right)$ and in the content on carbonylic compounds measured by the specific extinction coefficient at $270 \mathrm{~nm}\left(\mathrm{~K}_{270}\right)$. The SD values were more than $5 \%$. Limits established for the extra-virgin olive oil by EEC (2003) [Ref. 16]: $\mathrm{K}_{232} \leq 2.5$ and $\mathrm{K}_{270} \leq 0.22$

These results were in accordance with those reported by Malheiro et al. [17]. They mentioned that the maximum amounts of hydroperoxides were observed at 5 min of microwave heating. Being unstable primary oxidation products, the hydroperoxides are usually converted to secondary oxidation products, like aldehydes, alcohols, ketones, acids, dimmers, trimmers, polymers and cyclic compounds [18]. Additionally, such observation was previously proved by Malheiro et al. [4] and Yahyaoui et al. [2] when different Portuguese and Tunisian olive oils, from different commercial categories, were submitted to microwave heating.

Variation of the total phenolic content: As the amount of phenolic compounds is an important factor when evaluating the quality of olive oil, because of their involvement in its resistance to oxidation and its sharp bitter taste, this trial also aimed to determine the changes in the phenolic fraction of oils after a treatment for different microwave heating exposure times. With the increase in the exposure time all samples suffered 
drastic losses in the phenolic content, it ranged from 32.46 to $78 \%$ in olive oil enriched by mint and basil, respectively (Fig. 4). Our results are similar to those reported by Malheiro et al. [17]; in fact, Portuguese research team proved that the microwave heating brought significant changes to phenolic fraction of the olive oils in each exposition time, mainly between the olive oils with and without white tea extracts.

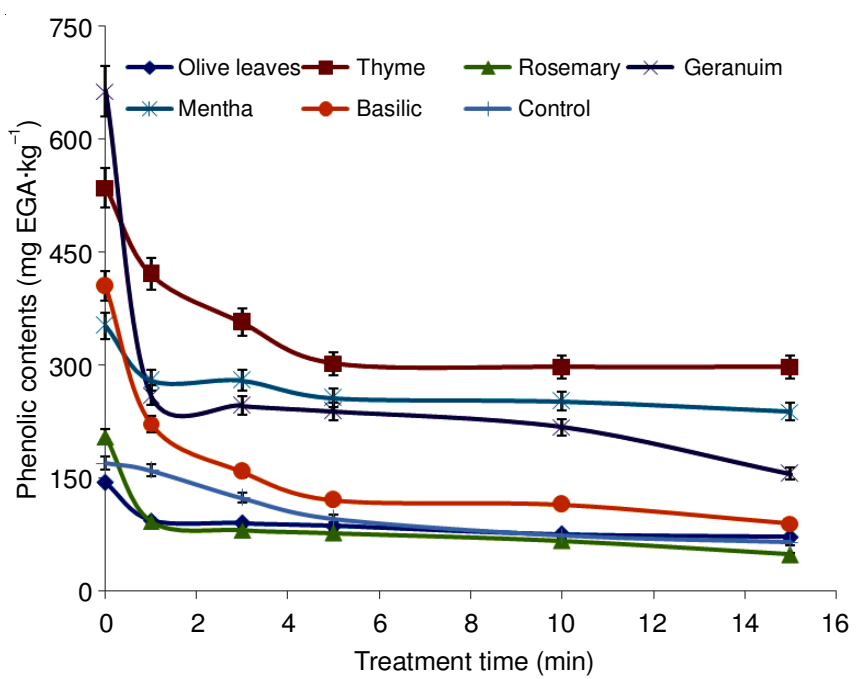

Fig. 4. Total phenolic content of enriched olive oil during microwaves treatment. The SD values were more than $5 \%$

Variation of chlorophyll and carotenoids contents: Chlorophylls are responsible for the greenish colouration of certain olive oils. Those pigments are also important in olive oil stability. Fig. 5 presents the change of chlorophyll contents in olive oils with aromatic and olive leaves extracts. The oil pigment content, mainly the chlorophyll fraction concentration, decreased gradually with the increase in the exposure time on microwaves. In all studied samples, the decrease of chlorophylls varied from 48 up to $90 \%$ of the initial value. On the other hand, carotenoid content followed a trend similar to the one of chlorophylls but the percentage loss was lower showing up to $80 \%$ loss for oil enriched with rosmary, geranium and mint, at the end of treatment (Fig. 5). While in olive oil enriched with olive leaves and basil extracts, the losses of carotenoid content was 57 and $55 \%$, respectively, from the initial content. The results of the present study are in accordance with Jaber et al. [19] who studied the stabilization of refined olive oil by enrichment with chlorophyll pigments extracted from Chemlali olive leaves. In addition, these results were in agreement with those founded by Malheiro et al. [17] and Yahyaoui et al. [2] who reported that microwave heating time decreased the total chlorophylls and carotenoids contents as long as the exposure time increases. In addition, Sevim et al. [20] mentioned that the improvement of oxidative stability and antioxidant activity of olive oils by the supplementation with olive leaf extract has been an important topic in the literature [21].

\section{Conclusion}

From the present study, we have demonstrated that phenolic compounds extracted from aromatic plants and olive leaves decrease the losses of quality in the analyzed olive oils until the $5 \mathrm{~min}$ of heating when compared to the control one.

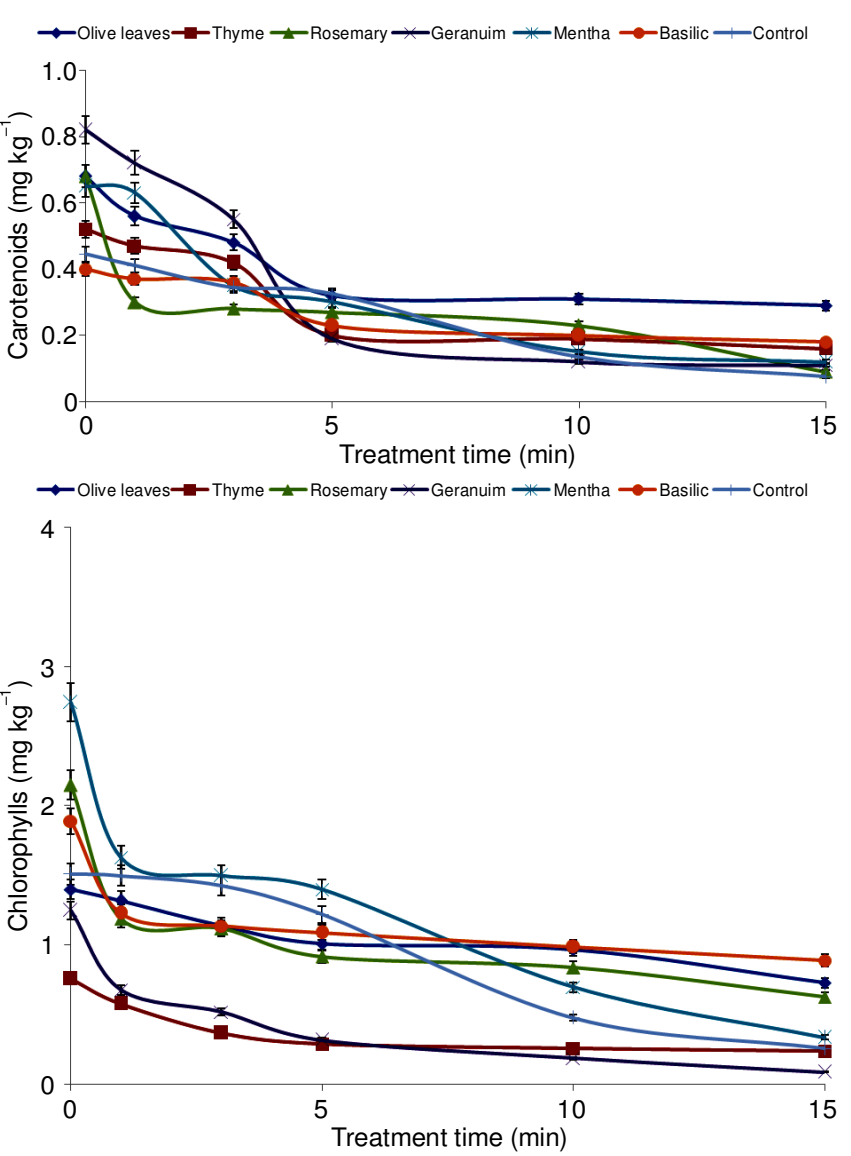

Fig. 5. Chlorophyll and carotenoid content of enriched olive oil during microwaves treatment. The SD values were more than $5 \%$

Aromatic plants and olive leaves extracts could be used as replacers to the synthetic antioxidants used by the industry. This is another line of investigation in order to valorize olive leaves as a sub-product from olive oil extraction industry.

\section{ACKNOWLEDGEMENTS}

The authors thank the Tunisian Ministry of Higher Education and Scientific Research for financial support and are grateful to Prof. Mohamed Rigane for useful discussions.

\section{REFERENCES}

1. V.B. Vikram, M.N. Ramesh and S.G. Prapulla, J. Food Eng., 69, 31 (2005); https://doi.org/10.1016/j.jfoodeng.2004.07.013.

2. A. Yahyaoui, G. Rigane and R.B. Salem, Biochem. Physiol., 3, 131 (2014); https://doi.org/10.4172/2168-9652.1000131.

3. R. Malheiro, N. Rodrigues, G. Manzke, A. Bento, J.A. Pereira and S. Casal, Ind. Crops Prod., 44, 37 (2013); https://doi.org/10.1016/j.indcrop.2012.10.023.

4. R. Malheiro, I. Oliveira, M. Vilas-Boas, S. Falcão, A. Bento and J.A. Pereira, Food Chem. Toxicol., 47, 92 (2009); https://doi.org/10.1016/j.fct.2008.10.014.

5. G.C. Peñalvo, V.R. Robledo, C.S.-C. Callado, M.J. Santander-Ortega, L. Castro-Vázquez, M.V. Lozano and M.M. Arroyo-Jiménez, Food Chem., 197, 509 (2016); https://doi.org/10.1016/j.foodchem.2015.11.002.

6. M. Moldao-Martins, S. Beirão-da-Costa, C. Neves, C. Cavaleiro, L. Salgueiro and M. Luísa Beirão-da-Costa, Food Qual. Prefer., 15, 447 (2004); https://doi.org/10.1016/j.foodqual.2003.08.001.

7. C.M. Asensio, V. Nepote and N.R. Grosso, J. Food Sci., 76, 445 (2011); https://doi.org/10.1111/j.1750-3841.2011.02332.x. 
8. M. Rosenblat, N. Volkova, R. Coleman, Y. Almagor and M. Aviram, J. Nutr. Biochem., 19, 514 (2008); https://doi.org/10.1016/j.jnutbio.2007.06.007.

9. O. Koprivnjak, D. Skevin, S. Valic, V. Majetic, S. Petrièevic and I. Ljubenkov, Food Chem., 111, 121 (2008);

https://doi.org/10.1016/j.foodchem.2008.03.045.

10. L. Rubió, M.J. Motilva, A. Macià, T. Ramo and M.P. Romero, J. Agric. Food Chem., 60, 3105 (2012); https://doi.org/10.1021/jf204902w.

11. M.A. Ayadi, N. Grati-Kamoun and H. Attia, Food Chem. Toxicol., 47, 2613 (2009); https://doi.org/10.1016/j.fct.2009.07.024

12. D.C. Costa, H.S. Costa, T.G. Albuquerque, F. Ramos, M.C. Castilho and A. Sanches-Silva, Trends Food Sci. Technol., 45, 336 (2015); https://doi.org/10.1016/j.tifs.2015.06.009

13. D. Boskou, Olive Oil: Chemistry and Technology, AOCS Press, Champaign, IL, p. 85 (1986)

14. M.I. Mínguez-Mosquera, M. Jarén-Galán, D. Hornero-Méndez, J. Garrido-Fernández, M.L. Gallardo-Guerrero and B. Gandul-Rojas, J. Am. Oil Chem. Soc., 68, 809 (1991); https://doi.org/10.1007/BF02660592.
15. D. Ocakoglu, F. Tokatli, B. Ozen and F. Korel, Food Chem., 113, 401 (2009); https://doi.org/10.1016/j.foodchem.2008.07.057.

16. European Union Commission Regulation 1989/2003. Off. J. Eur. Comm., 295, 57 (2003).

17. R. Malheiro, S. Casal, H. Lamas, A. Bento and J.A. Pereira, Food Res. Int., 48, 148 (2012); https://doi.org/10.1016/j.foodres.2012.03.005.

18. M. Laguerre, J. Lecomte and P. Villeneuve, Prog. Lipid Res., 46, 244 (2007); https://doi.org/10.1016/j.plipres.2007.05.002.

19. H. Jaber, M. Ayadi, J. Makni, G. Rigane, S. Sayadi and M. Bouaziz, Eur. J. Lipid Sci. Technol., 114, 1274 (2012); https://doi.org/10.1002/ejlt.201100176.

20. D. Sevim, O. Tuncay and O. Koseoglu, J. Am. Oil Chem. Soc., 90, 1359 (2013); https://doi.org/10.1007/s11746-013-2282-4.

21. K. Kiritsakis, M.G. Kontominas, C. Kontogiorgis, D. Hadjipavlou-Litina, A. Moustakas and A. Kiritsakis, J. Am. Oil Chem. Soc., 87, 369 (2010); https://doi.org/10.1007/s11746-009-1517-x. 